Upon the adoption of the changes in the student code and the printing of citation forms, the library began using citations to enforce the ban on food and drink in the stack areas. Immediately there was a noticeable improvement in student security assistant morale and a reduction of candy wrapper debris throughout the library. Table 1 is a summary of the number of citations issued since the program was implemented in October 1985.

As can be seen, there was an initial flurry of activity when the program was first implemented. More citations were issued in the last three months of 1985 than were issued in the first six months of the following year. Violations still do occur, but once patrons clearly understood that lack of compliance was punishable, most chose to remain in the student lounge with consumables. Although the major objective of the program was to enforce food and beverage policies, the system has proven useful in other ways.

The statistics in Table 1 indicate that the most frequent use of the citation system is for food and drink violations. However, failure to comply with an official and noise violations account for a number of issuances. Failure to comply with an official has proven to be a useful generic category. For example, citations in this category have been issued to patrons for such reasons as: a. the use of chewing tobacco, which is not allowed in the building;

b. non-compliance with the two-hour time limit for microcomputer use;

c. failure to leave the building at closing time;

d. non-compliance with group study room policies.

In addition, the prohibitions on defacement and misuse of university property have allowed assistants to fine patrons for such pranks as stealing signage or books and hiding them in the backpack of an unsuspecting friend.

Overall, the program has given the student security assistants the authority to enforce policies and cope with the peer pressure often associated with such a task. Certainly, the assistants find that most difficult patron situations can be handled with a warning and a verbal request for compliance. In fact, a the end of 1987, we stopped issuing citations for food and drink to freshmen and required an initial verbal warning. However, the occasional recalcitrant patron who refuses to comply presents a difficult dilemma. The citation system offers a solution to that problem and may prove a viable alternative to libraries with similar concerns.

\title{
Humor and creativity: A bulletin from the front lines in the war on mediocrity
}

\author{
By John Maxstadt \\ Instruction Librarian \\ University of Arkansas, Fayetteville
}

The University Libraries at Middle States University, a medium-size research institution, recently made headlines throughout academia as the result of a comprehensive library assessment performed by Maxine LeCouteau, the assistant director for library systems. LeCouteau's amazing findings, which were published in the prestigious journal Academic Library Update, indicated that the Middle States University Libraries performed at exactly the national average on all standard measures of library collections and services for academic and research libraries.

All of the Libraries' collections were of perfectly average size; circulation statistics matched the national average for academic and research librar- ies in every detail. The average number of interlibrary loan requests were received, and an average percentage were filled in the average length of time. The backlog in cataloging exactly duplicated the national average. The reference department routinely provided incorrect and incomplete answers to between $14.7 \%$ and $61.8 \%$ of all patron queries, ${ }^{1}$ the exact figure varying to match the latest estimated average published in the library research journals. Even patron theft and vandalism cost the Libraries a sum exactly equal to the national average.

${ }^{1}$ Ian Douglas, "Reducing Failures in Reference Service," RQ 28 (Fall 1988): 95. 


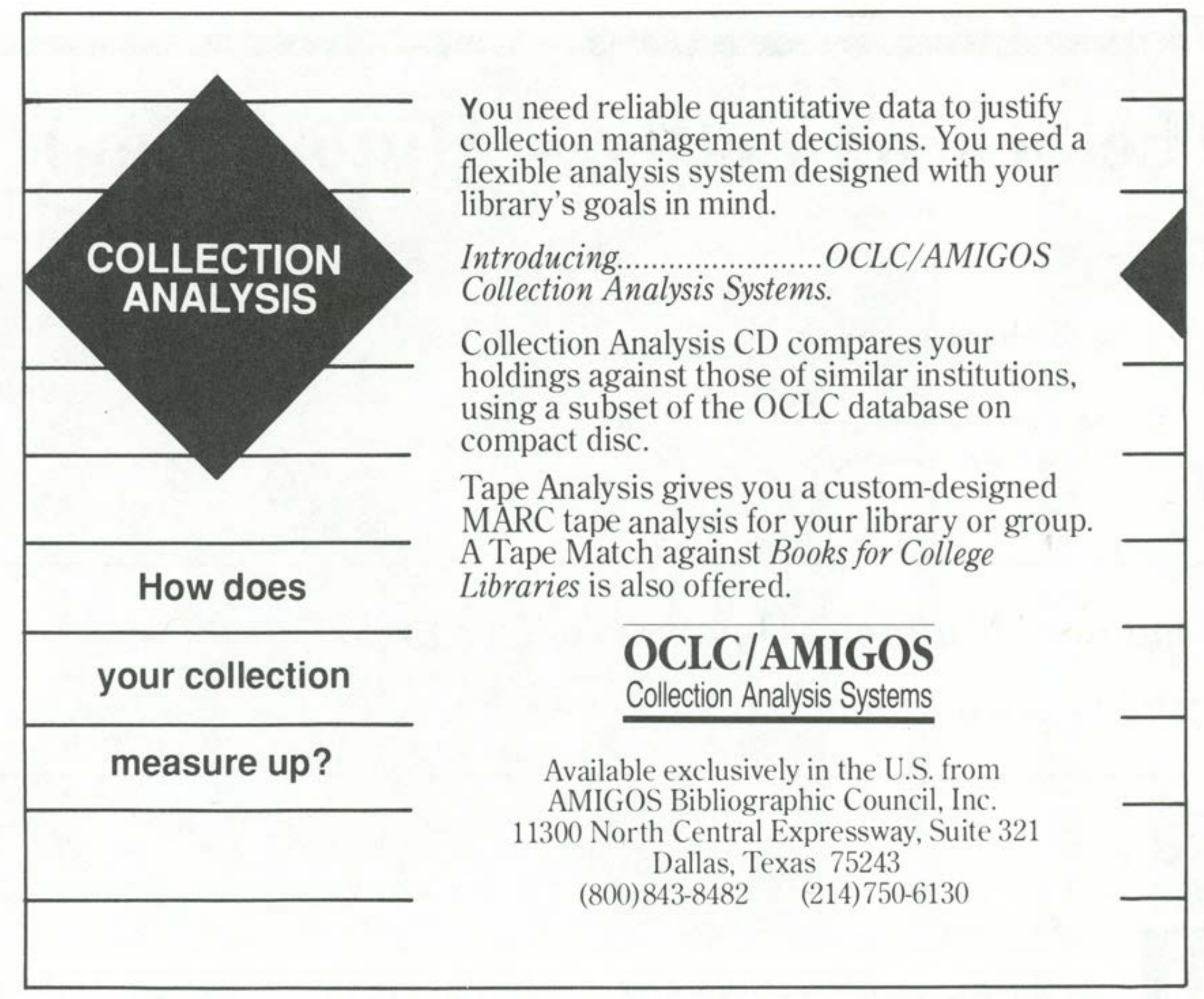

In a strongly worded statement to the University Committee on Academic Excellence, Vice Chancellor W. Frederick Bullington III declared, "Mediocrity, of this kind or of any kind, has no place in this institution's quest for excellence!" Bullington's indignation was echoed throughout the university community and in academic circles nationwide.

The editors of all the major library journals joined in condemning the mediocrity of the Middle States University library administration. Academic library associations around the country passed resolutions reaffirming their commitment to excellence and stating that mediocrity could never and would never be tolerated in academic librarianship.

Dr. Norman Cipher, director of libraries at Middle States University, immediately began a library assessment of his own to uncover areas in which his libraries performed above the national average. He was able to produce excellent and above-average performance evaluations dating back several years for nearly all of his staff, but withdrew them when faced with a study (recently conducted by LeCouteau) which showed that his evaluations exactly matched the national average for inflated ratings. Desperate, Cipher lobbied formerly sympathetic faculty for support, blamed his problems on budgetary restraints, and promised sweeping changes in library priorities and personnel. These actions merely added fuel to the fire, as it was pointed out that Cipher had done what any average library administrator would do in his situation.

Following an administrative vote of no confidence, Cipher resigned his position. The Library Committee unanimously voted to replace him with assistant director LeCouteau, who promised to eradicate library mediocrity wherever she found it. LeCouteau's new salary is considerably higher than the national average for academic library administrators.

Since his resignation, Dr. Cipher has been busy preparing a research study, to be presented at the annual meeting of the state Academic Library Association (due to scheduling conflicts and a tight honorarium budget, the association had been unable to attract a better speaker). Cipher has claimed that his preliminary results demonstrate that virtually $50 \%$ of all academic and research libraries function below the national average in any given area of collections or services, and that $50 \%$ of all library administrators and library employees perform below average level. It is rumored that he will name names.

Heads are expected to roll.

Editor's Note: John Maxstadt is instruction librarian at the University of Arkansas Libraries, which are, he tells us, "well above average in all respects." 